\title{
Lung mechanics and gas exchange in one-lung ventilation following contralateral resection
}

\author{
[La mécanique respiratoire et les échanges gazeux pendant la ventilation unilaté- \\ rale suivant une résection controlatérale]
}

Pedro Ruiz MD PhD, Garrett Kovarik MD

\section{Purpose:}

To describe the anesthetic management of a patient with previous left lower lobe resection who was submitted to a right upper lobectomy and review the changes in gas exchange and respiratory mechanics which occurred intraoperatively.

\section{Clinical features:}

A 69-yr-old male with lung cancer, emphysema and obstructive sleep apnea, presented for a right upper lobectomy. His history was also positive for a left lower lobectomy six years previously. Intraoperative lung isolation was achieved using a 4I F left double-lumen tube (DLT). Monitoring the respiratory mechanics allowed for continuous adjustment of ventilator settings during the various phases of the surgery avoiding the risks of barotrauma and volutrauma. Problems with oxygenation occurred during one-lung ventilation.

Conclusion: This case report shows that a severe level of hypoxemia and hypercarbia associated to lung mechanical property changes can be observed during the OLV phase. Application of continuous positive airway pressure on the nondependent lung partially corrected blood oxygenation. Lobe isolation techniques should be considered as useful options for intraoperative airway management for these patients.

Objectif: Décrire l'anesthésie d'un patient, ayant déjà subi la résection du lobe inférieur gauche, qui a été soumis à une lobectomie supérieure droite et revoir les changements peropératoires survenus dans les échanges gazeux et la mécanique respiratoire.

Éléments cliniques : Un homme de 69 ans, atteint de cancer du poumon, d'emphysème et d'apnée du sommeil, devait subir une lobectomie supérieure droite. L'isolement pulmonaire peropératoire a été réalisé à l'aide d'un tube 4 I F à double lumière gauche (TDL). Le monitorage de la mécanique respiratoire a permis le réglage continu des paramètres ventilatoires peropératoires et d'éviter les risques de barotrauma et de volutrauma. L'oxygénation a été problématique pendant la ventilation unilatérale (VUL).

Conclusion: Un niveau élevé d'hypoxémie et d'hypercapnie associé à des changements dans les propriétés mécaniques pulmonaires peut être observé pendant la VUL. La ventilation à pression positive constante du poumon non déclive a corrigé partiellement l'oxygénation sanguine. Les techniques d'isolement pulmonaire doivent être envisagées pour la prise en charge peropératoire des voies respiratoires de ce type de patients.

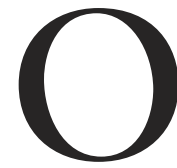
NE-LUNG ventilation (OLV) poses a greater challenge to the anesthesiologist when the ventilated lung has previously been submitted to resection. ${ }^{1}$ Following lung resection, exercise tolerance can decrease due to pulmonary hypertension and hypoxemia, which may not be evident at rest. ${ }^{2}$ We describe the management of a patient with previous left lower lobe resection who underwent right upper lobectomy, and the changes in gas exchange and respiratory mechanics during two-lung ventilation (TLV) and OLV at different patient positions. We review lung isolation options for similar cases. Institutional approval was obtained for the publication of the personal health information in this report.

\section{Clinical features}

A 69-yr old male was scheduled for right upper lobectomy for lung cancer. He presented with hemoptysis and secretions. Preoperatively, he had obstructive sleep apnea, treated with a continuous positive airway pressure (CPAP) device. His arterial hypertension and

From the Department of Anesthesia, Montreal General Hospital, McGill University Health Centre, Montréal, Québec, Canada. Address correspondence to: Dr. P. Ruiz, Montreal General Hospital, Department of Anesthesia, 1650, avenue Cedar, Room D10 165.3,

Montréal, Québec H3G 1A4, Canada. Phone: 514-934-1934, ext. 43261; Fax: 514-934-8249; E-mail: ppruizmd@aol.com Accepted for publication April 11, 2005

Revision accepted May 17, 2005. 
TABLE Arterial blood gases, arterial oximetry and respiratory mechanics in relation to patient position and ventilation

\begin{tabular}{|c|c|c|c|c|c|c|c|}
\hline $\begin{array}{l}\text { Position ventilation } \\
\text { procedure }\end{array}$ & $\begin{array}{l}\text { Supine } \\
\text { OLV } \\
\text { Clinical DLT } \\
\text { assessment }\end{array}$ & $\begin{array}{l}\text { Clinical } \\
\text { TLV } \\
\text { Foley } \\
\text { catheter }\end{array}$ & $\begin{array}{l}\text { Left lateral } \\
T L V \\
\text { Chest } \\
\text { incision }\end{array}$ & $\begin{array}{l}\text { Left lateral } \\
\text { OLV + no CPAP } \\
\text { Lobectomy }\end{array}$ & $\begin{array}{l}\text { Left lateral } \\
\text { OLV + no CPAP } \\
\text { Lobectomy }\end{array}$ & $\begin{array}{l}\text { Left lateral } \\
\text { OLV + no CPAC } \\
\text { Hemostasis }\end{array}$ & $\begin{array}{l}\text { Left lateral } \\
\text { TLV } \\
\text { Chest } \\
\text { closure }\end{array}$ \\
\hline $\mathrm{PaO}_{2}(\mathrm{mmHg})$ & 480 & 447 & $\begin{array}{ll}57 & 74\end{array}$ & 63 & 334 & & \\
\hline $\mathrm{SatO}_{2}(\%)$ & 91 & 99 & 99 & 88 & 93 & 89 & 100 \\
\hline $\mathrm{PaCO}_{2}(\mathrm{mmHg})$ & 39 & 32 & 53 & 66 & 60 & 63 & 57 \\
\hline $\begin{array}{l}\text { Inspiratory plateau } \\
\text { pressure }\left(\mathrm{cm} \mathrm{H}_{2} \mathrm{O}\right)\end{array}$ & - & - & 16 & 22 & 18 & 25 & 20 \\
\hline Cplat $\left(\mathrm{mL} \cdot \mathrm{cm} \mathrm{H}_{2} \mathrm{O}^{-1}\right)$ & - & 48 & 41 & 14 & 18 & 14 & 32 \\
\hline $\operatorname{Raw}\left(\mathrm{mL} \cdot \mathrm{sec}^{-1} \cdot \mathrm{cm} \mathrm{H}_{2} \mathrm{O}^{-1}\right)$ & - & 17 & 12 & 36 & 32 & 23 & 21 \\
\hline
\end{tabular}

$\mathrm{OLV}=$ one-lung ventilation; TLV = two-lung ventilation; $\mathrm{CPAP}=$ continuous positive airway pressure $; \mathrm{DLT}=$ double-lumen tube; $\mathrm{PaO}{ }_{2}$ $=$ oxygen arterial blood pressure; $\mathrm{PaCO}_{2}=$ carbon oxide arterial blood pressure $;$ Cplat $=$ respiratory compliance; Raw $=$ respiratory resistance.

emphysema were both optimized preoperatively. He reported a left lower lobectomy six years earlier. The physical examination was unremarkable except for obesity (body mass index $=33 \mathrm{~kg} \cdot \mathrm{m}^{-2}$ ). Pulmonary function tests revealed a forced vital capacity of 3.82 L ( $83 \%$ of predicted) and forced expiratory volume at one second of $2.95 \mathrm{~L}$ ( $81 \%$ of predicted) with poor bronchodilator response. The electrocardiogram showed right bundle branch block with secondary ST-T changes. A stress echocardiogram was clinically negative and electrically abnormal, although not diagnostic given baseline ST-T abnormalities. Left ventricular ejection fraction rose from a rest value of $65 \%$ to $75 \%$, with no regional wall motion abnormalities. During ventilatory exercise studies, he exercised to only $53 \%$ of predicted maximal oxygen consumption $\left(\mathrm{VO}_{2} \mathrm{max}\right)$, with an extremely abnormal response with marked hyperventilation, dyspnea and decreased $\mathrm{SpO}_{2}$ to $87 \%$. An echocardiogram showed no evidence of pulmonary hypertension.

Upon arrival in the operating room an iv radial artery cannula and a T5-6 epidural catheter ${ }^{1}$ were inserted. Propofol, fentanyl and rocuronium were used to induce anesthesia. A 41-F left double lumen tube (DLT) was inserted. Anesthesia was maintained with a remifentanil and propofol infusion, plus epidural boluses of $2 \%$ lidocaine with epinephrine. The patient was ventilated with an $\mathrm{FIO}_{2}$ of 1.0 throughout. Arterial blood gas analysis was performed during supine left OLV, and at the end of DLT inspection and lung auscultation, $\mathrm{SpO}_{2}$ dropped to $91 \%, \mathrm{PO}_{2}$ to $58 \mathrm{mmHg}$, with a $\mathrm{PCO}_{2}$ of $39 \mathrm{mmHg}$. $\mathrm{SpO}_{2}$ returned to normal as TLV was resumed, and ventilator settings were adjusted to a tidal volume (TV) of 600 $\mathrm{mL}$, aiming for an inspiratory pressure plateau lower than $30 \mathrm{~cm} \mathrm{H}_{2} \mathrm{O}$, rate of $8 \cdot \mathrm{min}^{-1}$ and I: E ratio $1: 2.5$. Fibreoptic bronchoscopy (FOB) confirmed correct DLT position.

We recorded the respiratory mechanics from a Datex-Ohmeda Captomac Ultima monitor M-CAiOV model (Bromma, Sweden) and calculated respiratory compliance dividing the TV by the inspiratory airway plateau pressure. After TLV resumed, arterial blood gases and respiratory mechanics were obtained in the supine position (Table). The DLT position was rechecked using FOB after lateral positioning of patient. Ten minutes after lateral positioning and establishment of TLV, arterial gases and respiratory mechanics were again recorded (Table). With OLV, TV was adjusted, aiming for a plateau pressure below $30 \mathrm{~cm} \mathrm{H}_{2} \mathrm{O}$. Ten minutes of OLV produced a decrease in $\mathrm{SaO}_{2}(88 \%)$, $\mathrm{PaO}_{2}(57 \mathrm{mmHg})$ and compliance $\left(14 \mathrm{~mL} \cdot \mathrm{cm} \mathrm{H}_{2} \mathrm{O}^{-1}\right)$ and increase in $\mathrm{PaCO}_{2}(66 \mathrm{mmHg})$ respiratory resistance $\left(36 \mathrm{~mL} \cdot \mathrm{sec}^{-1} \cdot \mathrm{cmH}_{2} \mathrm{O}^{-1}\right)$ and airway plateau pressure $\left(22 \mathrm{~cm} \mathrm{H}_{2} \mathrm{O}\right)$ (Table). Again, FOB confirmed correct DLT positioning. Extensive bronchial secretions were suctioned from the dependent lung. After manual partial re-expansion of the non-dependent lung, $5 \mathrm{~cm} \mathrm{H}_{2} \mathrm{O}$ CPAP was applied, with an increase of $\mathrm{PaO}_{2}$ to $74 \mathrm{mmHg}$ and $\mathrm{SpO}_{2}$ to $93 \%$. At this point, $\mathrm{PCO}_{2}$ was $60 \mathrm{mmHg}$, and values for airway pressure plateau, compliance, and resistance were 18,18 and 32 respectively (Table). These values remained constant throughout the right upper lobectomy (approximately $90 \mathrm{~min}$ ). At the request of the surgeon CPAP $5 \mathrm{~cm} \mathrm{H}_{2} \mathrm{O}$ was removed, with immediate worsening of $\mathrm{SpO}_{2}(89 \%), \mathrm{PaO}_{2}(63 \mathrm{mmHg})$ and $\mathrm{PaCO}_{2}(63$ $\mathrm{mmHg}$ ). Airway plateau pressure, compliance, and resistance were $25 \mathrm{~cm} \mathrm{H}_{2} \mathrm{O}, 14 \mathrm{~mL} \cdot \mathrm{cm} \mathrm{H}_{2} \mathrm{O}^{-1}$ and 23 $\mathrm{mL} \cdot \mathrm{sec}^{-1} \cdot \mathrm{cm} \mathrm{H}_{2} \mathrm{O}^{-1}$, respectively (Table). Oxygenation 
improved when TLV was restarted. Although the respiratory rate was increased to $15 \cdot \mathrm{min}^{-1}, \mathrm{PaCO}_{2}$ was $57 \mathrm{mmHg}$ during TLV, probably due to bronchial secretions. Plateau pressure was $20 \mathrm{~cm} \mathrm{H}_{2} \mathrm{O}$, compliance was $32 \mathrm{~mL} \cdot \mathrm{cm} \mathrm{H}_{2} \mathrm{O}^{-1}$ and resistance was 21 $\mathrm{mL} \cdot \mathrm{sec}^{-1} \cdot \mathrm{cm} \mathrm{H}_{2} \mathrm{O}^{-1}$ (Table). Hematocrit dropped from $48 \%$ to $42 \%$ and there were no clinically significant cardiovascular changes during surgery. The patient was extubated in the operating room with adequate analgesia, spent six hours in the postanesthesia care unit, and was discharged after an uncomplicated hospital stay on the fifth postoperative day.

\section{Discussion}

This case illustrates the difficulties in managing patients requiring OLV after previous contralateral lung resection. This procedure will become more frequent as the population ages, life expectancy increases after first resection, and diagnostic methods improve the odds of finding a second lesion during follow-up of the first intervention. OLV is then replaced by an even more challenging scenario: one lobe, or at most two-lobe ventilation. There are no controlled studies describing respiratory mechanics in these patients. Sporadic communications reporting gas exchange have been published. ${ }^{1,3}$

After lung resection, a series of cardiopulmonary changes and adaptations are expected to occur in the remaining lung tissue, and are a function, in part, of the size of lung resection. Our patient's stress echocardiogram test was aborted due to exertional dyspnea, and during the ventilatory exercise studies, he exercised only to $53 \%$ of predicted $\mathrm{V}_{2}$ max. He developed an abnormal response with marked hyperventilation and desaturation to $87 \%$. Reduced exercise tolerance after pulmonary resection is related to pulmonary hypertension. ${ }^{4}$ Changes in hemodynamics, before and after pulmonary resection, do not necessarily correlate with changes in pulmonary function, making it more difficult to predict perioperative complications. Patients with a normal preoperative PFT may have cardiovascular decompensation. ${ }^{2}$ Response to the stress test in our patient can be explained based upon this finding. Some attribute reduced stroke volume index after pneumectomy to impaired filling of the left ventricle consequent to reduced pulmonary blood volume. ${ }^{4}$ The same occurs after lobectomy, although less significantly. ${ }^{4}$ Other potential changes after pneumectomy include decrease in lung diffusion capacity, and elevation in right heart pressure during exercise. ${ }^{2}$

After OLV was established, we expected to observe changes in gas exchange. As seen in this case, the level of hypoxemia and hypercapnia can reach critical levels very rapidly. When supine, during DLT position assessment, desaturation became critical shortly after OLV. Arterial gas analysis should have been utilized at this point as a predictor for gas exchange during intraoperative OLV in the lateral position, and a different approach for right lung isolation could have been planned at that time. A selective endobronchial blocker prior to turning the patient on lateral decubitus should have been considered.

When dealing with lung isolation for contralateral lung resection, it is also important to consider respiratory mechanics. A summation of factors can render lung isolation more dangerous than usual OLV. Tidal volume may be delivered to pulmonary parenchyma that is not prepared to recruit more alveolar units, as a result of maximum expansion after previous resection. This situation can lead to barotrauma, ventilation/perfusion mismatch, and increases in pulmonary vascular resistance, leading to ventilatory and hemodynamic compromise. If a DLT is used to achieve lung isolation, it is important to record baseline flowvolume loops, and to monitor respiratory mechanics, before and during lung isolation. One should also be prepared to adjust ventilator settings before complications arise. While inspiratory peak pressure and inspiratory plateau pressure are both useful, the latter is less influenced by DLT flow resistance. The ideal ventilation mode is pressure control ventilation. In pressure control mode, if there is a reduction in delivered TV, or if in volume control mode inspiratory plateau levels rise above $30 \mathrm{~cm} \mathrm{H}_{2} \mathrm{O}$, one should first exclude DLT malposition by FOB examination. Afterward, a new ventilatory strategy should be instituted, minimizing inspiratory pressures with low TV and high respiratory rate. During lung isolation, there is also a risk of a life-threatening pneumothorax in the dependent hemithorax. High inspiratory plateau pressures might be associated with high pulmonary vascular resistance, increasing afterload to the right ventricle, further compromising its function due to hemodynamic adaptations occurring in response to previous pulmonary resection. Different from OLV, when there are two or three lobes from which the vascular bed can be recruited to adjust right ventricular output, in one-lobe ventilation there is minimal reserve of the vascular bed that can be recruited to reduce right ventricle afterload.

Campos $^{5}$ successfully managed a critical situation by isolating the lobe to be resected using a Univent tube (Fuji Systems Corp., Tokyo, Japan) in a patient with bronchial hemorrhage and previous contralateral lobectomy. That patient did not maintain adequate oxygenation during total lung isolation even after 
application of CPAP, different from our patient. Later, the same author investigated the effects on oxygenation during selective lobar $v s$ total lung collapse, with and without CPAP. He observed higher arterial oxygen tension with selective lobar isolation. ${ }^{6}$ Isolation of the lobe to be resected, and ventilation of the remaining lung is a reasonable alternative to be considered. McGlade and Slinger recently described the successful management of a case similar to ours. ${ }^{7}$ They used a left DLT combined with an Arndt wire-guided endobronchial blocker (Cook, Bloomington, IN, USA) to isolate the lobe to be resected. During the right upper lobectomy, $2 \mathrm{~cm} \mathrm{H}_{2} \mathrm{O}$ CPAP was applied to the middle and lower right lobes through the bronchial blocker (BB). The removal of CPAP at the surgeon's request provoked a worsening of oxygenation only 15 min after beginning one-lobe ventilation, at levels similar to our case. Lobar isolation techniques make ventilation of non-dependent lung areas possible to deliver better oxygenation, although with more technical difficulty and with a higher risk of intraoperative $\mathrm{BB}$ dislocation. Correcting BB dislocation in a patient in the lateral position is not always simple, particularly when devices such as the Arndt BB are used. Arndt $\mathrm{BB}$ positioning depends upon the orientation of the blocker by FOB, using the wire loop located at the $\mathrm{BB}$ tip. ${ }^{8}$ Once the blocker is positioned, the wire is removed, making $\mathrm{BB}$ repositioning impossible.

In conclusion, in a patient with a previous contralateral lung resection monitoring respiratory mechanics allowed continuous adjustment of the ventilator settings during the various phases of surgery, avoiding the risks of barotrauma and volutrauma. Changes in respiratory mechanics and gas exchange are anticipated if contralateral lung isolation is established with a DLT in patients with previous lung resection. Lobe isolation techniques should be considered useful options, keeping in mind though, that a BB might be associated with difficulties in maintaining lobe isolation due to intraoperative dislocation of the blocker position.

\section{Acknowledgement}

We are thankful to Emilio Cabanas, RT for helping us with the gas blood analysis and respiratory mechanic recordings.

\section{References}

1 Ruiz Neto PP. One-lobe ventilation or the hazard of bilateral upper lobectomy (Letter). J Cardiothorac Anesth 1989; 3: 254-5.

2 Nishimura H, Haniuda M, Morimoto M, Kubo K. Cardiopulmonary function after pulmonary lobectomy in patients with lung cancer. Ann Thorac Surg 1993; 55: 1477-84.

3 Hagibira S, Maki N, Kawaguchi M, Singer P. Selective bronchial blockage in patients with previous contralateral lung surgery. J Cardiothorac Anesth 2002; 16: 638-42.

4 Heerdt PM. Cardiovascular adaptation to lung resection. In: Kaplan JA, Slinger PD (Eds). Thoracic Anesthesia, 3rd ed. Philadelphia: Churchill Livingstone Inc.; 2003: 423-35.

5 Campos JH, Ledet C, Moyers JR. Improvement of arterial oxygen saturation with selective lobar bronchial block during hemorrhage in a patient with previous contralateral lobectomy. Anesth Analg 1995; 81: 1095-6.

6 Campos JH. Effects on oxygenation during selective lobar versus total lung collapse with or without continous positive airway pressure. Anesth Analg 1997; 85: 583-6.

7 McGlade DP, Slinger PD. The elective combined use of a double lumen tube and endobronchial blocker to provide selective lobar isolation for lung resection following contralateral lobectomy. Anesthesiology 2003; 99: 1021-2.

8 Arndt GA, Kranner PW, Rusy DA, Love R. Single-lung ventilation in a critically ill patient using a fiberoptically directed wire-guided endobronchial blocker. Anesthesiology 1999; 90: 1484-6. 